\title{
Research sans frontières
}

\author{
Academy report finds that international collaboration is on \\ the rise, and should not be seen as an 'easy target' for cuts.
}

\section{BY NATASHA GILBERT}

S cientists used to interact with colleagues based abroad mainly at conferences. These days they are increasingly meeting at the lab bench, says a report by the Royal Society, Britain's national academy of science. More than $35 \%$ of all articles published in international journals are now the product of such collaboration, an increase of $10 \%$ in 15 years, says the study, Knowledge, Networks and Nations: Global Scientific Collaboration in the 21st Century.

Collaboration can boost citation impact, spread costs and broaden research horizons. It has, for example, enabled researchers at the International Rice Research Institute in Los Baños, the Philippines, to tackle scientific questions on a scale once thought impossible, says Robert Zeigler, director-general of the institute, which is part of the developing world's network of agricultural research centres - known as the Consultative Group on International Agricultural Research (CGIAR).

The CGIAR used to be "physically isolated from the advanced research institutes" in developed countries, says Zeigler. Today, the centres have partnerships with world-leading labs in Europe and the United States, working on challenging projects such as re-engineering photosynthesis in rice to be more efficient. "This would have been unheard of a decade ago," says Zeigler.

The Royal Society's study, published on 28 March, finds that collaboration involving US scientists has grown the most during the past 15 years. The number of papers published with lead authors based in the United States and collaborators abroad has risen from about 50,000 in 1996 to around 95,000 in 2008. But the new total represents just $29 \%$ of the US research output. By contrast, almost half of all Germany's research output in 2008 involved international collaborations (see 'A world of collaboration').

The numbers are not rising across the board, however. Although in China collaboration is increasing overall, it is "not keeping pace with the even more dramatic rise in its overall publication productivity", according to the report. As a proportion of China's annual national output, papers based on international collaboration fell from around 18\% in 1996 to 15\% in 2008 . Other nations whose science base is growing rapidly, such as Brazil, show similar trends.

Each collaborating country increases a paper's impact, up to a tipping point of about ten countries, the report says. In some cases, the effect can be dramatic. Compared with papers by authors in Mexico alone, those with authors in both Mexico and Germany had three times the impact. And for authors in Russia, collaboration with researchers in Canada boosted impact by a factor of almost five.

For the traditional science powers, collaborating with up-and-coming countries such as China and Brazil is not just about increasing research impact, says Jonathan Adams, director of research-performance analysts Evidence, part of Thomson Reuters, in Leeds. "It's about keeping in touch with what they are doing," he says.

The report notes that "the scientific superpowers of the 20th century remain strong". But it warns these governments against viewing multinational research efforts as "easy targets" for spending cuts during tight fiscal times. Doing so, it says, could isolate national science activities, threatening quality and impact.

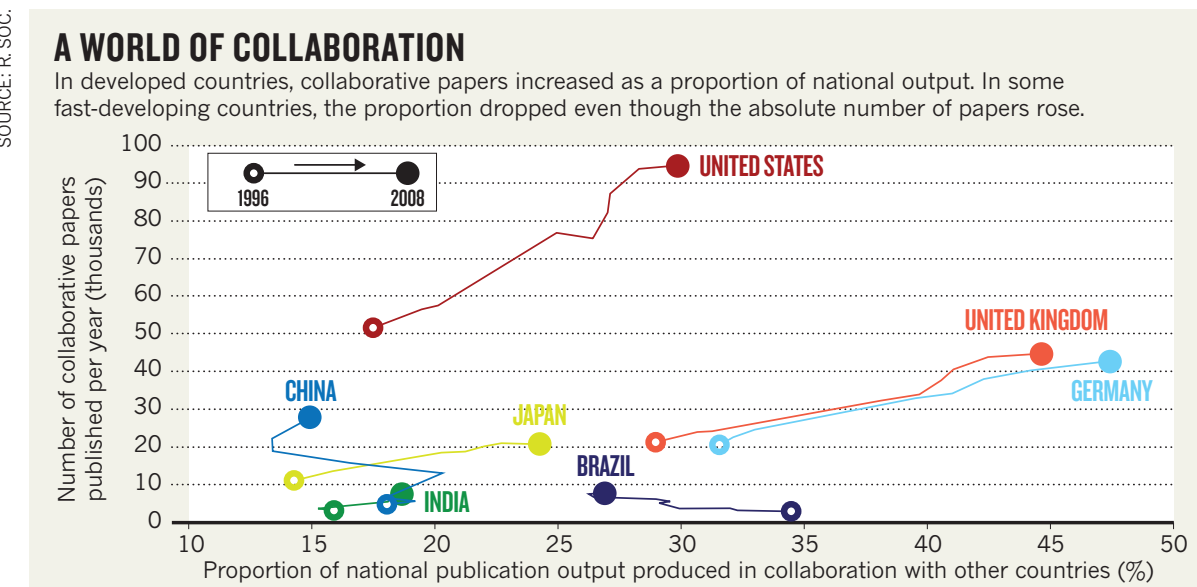

